\title{
Lugar de los migrantes en territorio sacro
}

\section{The Place of Migrants within the Sacred Territory}

\author{
Patricia Fortuny Loret de Mola'
}

Ciesas Peninsular, Mérida, Yucatán, México

mpfortuny@gmail.com

\section{RESUMEN}

A mediados del siglo pasado autores clásicos como Herberg (1960) y Handlin (1973) afirmaban que la religión era un elemento central en la vida de los inmigrantes. Analistas recientes (Williams, 1988; Warner, 1998; Tweed, 1997; Orsi, 2002) coinciden con los clásicos citados arriba; sin embargo, los últimos incluyen en su discusión nuevas variables sociológicas. Hirschman (2004) interroga el modelo clásico y reflexiona sobre los estudios posteriores que han relativizado estas afirmaciones. En este documento, por un lado, analizo la creencia desde la perspectiva que apuesta por la fuerza que puede tener este factor entre migrantes, y por el otro, utilizo un enfoque que toma en cuenta el origen y destino, tipo de iglesias, líderes espirituales y políticas eclesiásticas y de cómo estos inciden en la transformación de la religiosidad de los migrantes. Para ilustrar las diversas posiciones que ocupan los migrantes en el péndulo de lo sagrado utilizo casos empíricos en donde algunos quedan en el centro de la creencia, otros pueblan los espacios intermedios y muchos más inundan la periferia. Este tema ha sido poco atendido en los estudios sobre migración y religión.

1 Licenciada en Antropología Social por la Universidad Autónoma de Yucatán (UADY); maestría en Gobierno y Política en América Latina por la Universidad de Essex, Gran Bretaña y doctorado en Antropología Social por la University College London, Gran Bretaña. Ha publicado tres libros, decenas de artículos, capítulos y reseñas en español e inglés sobre religión y migración internacional. Laboró como docente por más de diez años en la UADY. Es profesora/investigadora titular C en el Centro de Investigaciones y Estudios Superiores en Antropología Social o Ciesas desde 1988. En el Sistema Nacional de Investigadores o SNI tiene nivel II desde 2002 y ha pertenecido al SNI en forma ininterrumpida desde 1989. 


\section{PALABRAS CLAVE}

Migrantes, creencia, prácticas religiosas, no afiliados

\section{ABSTRACT}

In the middle of the last century classical authors such as Herberg (1960), and Handlin (1973), claimed that the religion was central in immigrant's life. Recent analysts (WiIliams, 1988; Warner, 1998; Tweed, 1997; and Orsi, 2002) coincide with the classics listed above, however the latter include in their discussion new sociological variables. Hirschman (2004) interrogates the classical model and reflects on subsequent studies. Here, I analyze religious practice, from the perspective of the strength and frequency of the sacred, and also taking into account the influence of factors such as place of origin, destination, spiritual leaders, and ecclesiastical policies, can have on religious transformation among immigrants. To illustrate the positions occupied by migrants on the pendulum of the sacred I use empirical cases where some of them stay in the center, others rely in the intermediate spaces and many more move around the periphery. This topic has had little attention if any, among studies on migration and religion.

\section{KEYWORDS}

Migrants, belief, religious practice, unaffiliated

Many old and new immigrants are indifferent, if not hostile, to organized religion

(Hirschman, 2004, p. 1207)

\section{Introducción}

Con la finalidad de abordar la religiosidad en toda su diversidad resulta imprescindible descentrar el estudio de la religión de tal forma que sea posible incluir aquellos fieles que encontramos al filo de lo sagrado, ya sea porque se han alejado de la fe, o porque han quedado fuera de las instituciones religiosas y/o más allá de una estructura u organización más o menos coherente. En lugar de asumir que la religiosidad permanece en determinados espacios confinados, se puede avanzar en el análisis si se piensa en entornos que hablan de la circulación, el movimiento, ensamblaje y los distintos enlaces que se dan sobre la marcha. La fluidez de la creencia se halla entre poblaciones móviles, tal vez con más frecuencia de lo que se había supuesto. 
Es fundamental admitir que el papel de la instituciones religiosas en una sociedad dada no es ni puede ser siempre aquella que procura agencia, poder o que funciona en la dimensión del progreso y de lo positivo; algo que olvidan algunos estudiosos de la religión. Cuando esto sucede escapa a la mirada del investigador la presencia del lado patriarcal, autoritario, dogmático, manipulativo (Cadge, Levitt y Smilde, 2011) que la creencia también acarrea. Al considerar la existencia del pluralismo religioso que tanto se ha contendido en las últimas dos décadas tanto en América Latina como en Estados Unidos, es preciso distinguir que no todas las religiones gozan de igual apertura y libertad al ser puestas en práctica. Cada analista cuenta con su formación epistemológica que en ocasiones conlleva un cierto grado de identificación con una u otra confesión. En mi investigación sobre la organización evangélica La Luz del Mundo en Houston, Texas, por ejemplo, señalo numerosas ventajas entre los creyentes, como las redes sociales, el capital social, la agencia, las fuentes de información sobre empleos, la vivienda, las escuelas, los hospitales y muchos otros servicios que son imprescindibles para integrarse a la vida en otro país. Sin embargo, no siempre advertí que mientras la comunidad religiosa le proporcionaba importantes formas de conocimiento al migrante, a la vez determinaba, impulsaba y promovía, usando cierto grado de coerción, aquellos grupos con los que podía interactuar y grupos con los que era preferible no hacerlo en la vida social que quedaba más allá de los confines de la convivencia religiosa (Fortuny Loret de Mola, 2002)2.

Con el objetivo de mostrar en este artículo las diversas posiciones en donde se ubican los migrantes en el espacio religioso, presento una suerte de tipología flexible para entender el constante movimiento de creyentes y no creyentes. Algunos se encuentran en el centro de la creencia, otros pueblan los sitios intermedios y muchos más inundan la periferia. Grace Davie (1994) construyó la categoría de «creer sin pertenecer», que considero valiosa en el tiempo presente ya que es capaz de explicar el comportamiento de amplios sectores de la población migrante y no migrante.

En la primera parte del texto discuto, por un lado, la perspectiva teórica (Herberg, 1960 y Handlin, 1973) que prevaleció en las décadas de 1960 y 1970, que suponía que la religión era un contenido central en la vida del inmigrante en Estados Unidos, y, por el otro, las contribuciones que hicieron autores recientes, quienes añadieron factores más sociológicos

2 Observé que estas cosas ocurrieran entre jóvenes salvadoreños en Houston, Texas, entre 1999 y 2000 . Muchos de ellos no pertenecían a liguillas de fútbol en el medio debido a que, en esos espacios, los presentes ingerían bebidas alcohólicas después de los partidos. En consecuencia, los creyentes de El Salvador tenían pocas o nulas posibilidades de conocer e interactuar con otros inmigrantes que hubieran podido enriquecer sus redes sociales. 
aunque se mantuvieron en la misma vertiente. Recurro también a Charles Hirschman (2004), puesto que hace nuevas aportaciones al tema y completa el análisis al incluir la discusión sobre la influencia que tuvieron y tienen los inmigrantes en el panorama religioso de Norteamérica. En la segunda parte demuestro, a través de diversos casos empíricos correspondientes a la primera década del siglo XXI, que en realidad existe una amplia diversidad de posiciones que los migrantes ocupan en torno a lo sagrado. En esta misma sección, para completar el argumento relativo a las diversas formas que los migrantes mexicanos adoptan al vincularse con las instituciones religiosas en el lugar de destino, presento datos estadísticos del Pew Research Center (2015) que arrojan información sobre el crecimiento de hispanos (latinos) no afiliados ${ }^{3}$. Estas cifras muestran desde la perspectiva cuantitativa los cambios y, sobre todo, la tendencia que existe en el paisaje religioso norteamericano en los últimos siete años (2007 a 2014), que por supuesto incluye a aquellos que son mexicanos de origen, a los que residen en el país del norte, así como a los millones de inmigrantes que carecen de documentos migratorios. La reflexión y el diálogo teórico se derivan del contenido de entrevistas y observaciones realizadas entre mexicanos que residen en los Estados Unidos y/o aquellos que ya retornaron a México ${ }^{4}$.

\section{Primera parte}

\section{La «estrecha» relación entre migración y religión}

La idea que dominaba entre los estudiosos que abordaron el tema de la religión de los inmigrantes europeos que Ilegaron a Estados Unidos durante los siglos XIX y principios del XX tiene su origen en el modelo clásico o la tesis de Handlin (1973) y Herberg (1960), que escriben desde la década de 1950, aunque se dan a conocer en forma más amplia durante los años 60 y 70 . Si bien Handlin y Herberg subrayaban los beneficios psicosociales que la creencia brindaba a los nuevos pobladores de Norteamérica, esto acarreaba en muchas ocasiones un sinnúmero de problemas.

Oscar Handlin, en su libro The Uprooted (1973), afirma el dominio que tenía la religión en la vida de los inmigrantes. «The very process of adjusting immigrant ideas to the conditions of the United States made religion

3 De acuerdo con el PewResearchCenter, se incluyen entre los no afiliados o unaffiliated en inglés, a los que se autodefinieron como ateos, agnósticos o quienes respondieron no pertenecer a «nada en particular».

4 Los testimonios del texto se derivan de varios proyectos de investigación realizados en Yucatán, México — que constituye el lugar de origen de una buena parte de los creyentes-, y de proyectos efectuados en diversos destinos, en los estados de Texas, California, Florida y Georgia en Norteamérica. El trabajo etnográfico en esta temática en general se realizó de 2000 a 2012. 
paramount as a way of life» (1973, p. 105). La existencia en el nuevo país había arrancado al inmigrante de su espacio geográfico en su comunidad, de sus tradiciones y de todo aquello que lo ataba a su estilo de vida anterior; lo único que permanecía para adherirse a ese nostálgico pasado era la religión, a tal grado que esta se fortificaba en el destino más que en el lugar de origen.

In the American environment, so new and so dangerous, these people felt more need than ever for the support of their faith. Yet the same environment, in its very strangeness and looseness and freedom, made it difficult to preserve what could be taken for granted at home. [...] Their religious life accordingly grew rigid; they became far more conservative than those of their fellows who had remained in Europe (1973, p. 127).

Will Herberg escribió Protestant, Catholic, Jew (1960), alentado por un apasionado entusiasmo casi espiritual sobre lo que se sabía en ese tiempo, acerca del extraordinario incremento que se había dado en la primera mitad del siglo $X X$, en las tres Iglesias de la «América» ${ }^{5}$ compuesta por inmigrantes de toda Europa. Para este autor, la afiliación religiosa no solo otorgaba a los «americanos» un lugar en la sociedad, sino que también les ayudaba a entenderla. El largo proceso de «americanización» se daba a través de los nietos de los europeos, que habían nacido en el Nuevo Mundo. La tesis de Herberg consistía en que tanto los inmigrantes como las nuevas generaciones encontraban un lugar para identificarse con la vida americana, precisamente en la religión (protestante, católica o judía). Según una ilustrativa reseña en donde Schwartz (2004) reconsidera Protestant-Catholic-Jew a la luz del presente, afirma que el análisis de Herberg continúa dialogando con la situación actual solo en el sentido de que el país se caracteriza por tener una religiosidad amplia, más no particularmente profunda (2004, p. 124).

Whether we judge by religious identification, church membership, or church attendance, whether we go by the best-seller lists, the mass media, or the writings of intellectuals, the conclusion is the same: there is every sign of a notable «turn to religion» among American people today (1960, p. 1). The pervasiveness of religious identification may safely be put down as a significant feature of the America that has emerged in the past quarter of a century (1960, p. 47).

Charles Hirschman (2004) critica el modelo de Handlin y Herberg porque considera que desatienden el papel crucial que las instituciones

5 Utilizo los vocablos América y americanos entre comillas, porque desde y para América Latina son Norteamérica y norteamericanos, respectivamente. 
religiosas desempeñan en Estados Unidos como proveedoras de información que incrementa las oportunidades socioeconómicas de los inmigrantes así como de las generaciones posteriores. Es decir, no se interesaron en estudiar cómo es que contribuyen los colectivos religiosos y las congregaciones con la movilidad social y económica. En palabras de Hirschman:

The creation of an immigrant church or temple often provided ethnic communities with refuge from the hostility and discrimination from the broader society as well as opportunities for economic mobility and social recognition (2004, p. 1206).

En contraste con la idea dominante en la obra de Herberg, sobre la estrecha relación entre pertenencia religiosa e identidad norteamericana, Hirschman alega que no existe una sola interpretación en cuanto al papel de la religión en el proceso de adaptación del migrante, «just as there is no single path to assimilation in American Society. Many old and new immigrants are indifferent, if not hostile, to organized religion» (2004, p.1207, el subrayado es mío).

El viejo modelo, aunque con nuevas ideas que daban cuenta de la importancia de la religión en la formación de la identidad, por ejemplo, siguió vigente en la literatura de fines de los años 80 , como cuando se hablaba de ciudades puerta o Gateway cities. Raymond B. Williams (1988), en su estudio sobre inmigrantes de Paquistán y de la India en Estados Unidos, quedó convencido del destacado papel que cumple el aspecto sagrado, cuando señala que: «Los inmigrantes son religiosos desde cualquier punto de vista, mucho más de lo que eran antes de dejar su casa, porque la religión es un importante sello de identidad que les ayuda a preservar tanto su ser individual como la cohesión de grupo» (1988, p. $11)^{6}$. Líneas adelante, Williams insiste en la centralidad que ocupa la religión en Estados Unidos, donde posee un claro e indiscutible significado que le brinda aceptación en la sociedad destino. En consecuencia, el énfasis en la afiliación e identidad religiosa es una de las principales estrategias que permite al inmigrante mantener su propia identidad, al mismo tiempo que adquiere prestancia y aceptación en la comunidad (Williams, 1988). Hace más de 20 años, el contexto sociopolítico de Estados Unidos era muy diferente al contexto de «seguridad nacional» que prevalece en la actualidad; en ese entonces, la identidad religiosa de un musulmán podía ser de mucha ayuda para identificarse positivamente dentro de su

6 El mismo Williams afirmaba que muchos jóvenes profesionistas que entrevistó durante su estudio de campo admitieron que no eran muy devotos cuando asistían a la universidad en India o en Paquistán, pero, una vez que habían llegado a Estados Unidos, hasta se ocupaban de llevar a sus familias al templo o a la mezquita con regularidad. 
comunidad india, así como frente a la sociedad más amplia del país anfitrión. En el presente, la identidad religiosa de musulmán se ha convertido en un estigma frente al resto de la sociedad norteamericana y puede acarrear riesgos inesperados, como ser detenido al salir o entrar a Estados Unidos, a veces solo por tener un nombre que lo asocia con la religión islámica.

En trabajos más recientes como el de Stephen Warner $(1998$, p. 3) aún persistía esta vieja idea de la fuerza religiosa entre inmigrantes. Warner señala que las «identidades religiosas frecuentemente (aunque no siempre), significan más cuando están lejos de casa, en la diáspora, que lo que significaban anteriormente para ellos». La religión al parecer es capaz de responder a preguntas sobre el sentido, que surgen a partir de la experiencia de la migración. De igual modo Timothy Tweed (1997, p. 29) en su investigación sobre cubanos en Miami, indica que para darle un nuevo significado a sus vidas, como gente desplazada y dispersa, los inmigrantes de la Isla recurrieron a la religión tanto en las iglesias como en los hogares, con lo que esta se hizo aún más necesaria. Robert Orsi (2002) refuerza este argumento en su estudio sobre los italianos que se asentaron en Harlem, Nueva York. Este autor opina que la religión es clave en el proceso de afirmar los lazos con el lugar de origen, así como para mantener la «identidad cósmica y psíquica de los inmigrantes» (2002, p. 168).

Mi experiencia en la primera década del siglo XXI ha sido distinta, como se verá en las siguientes páginas. Considero que existe un amplio abanico de respuestas y de dimensiones en ese sentido. El celo y la devoción religiosa están estrechamente asociados al líder espiritual y al tipo de pastoral católica (si este fuera el caso). La vinculación entre la creencia y la migración no es directa o automática, como señala Herberg; más bien esta relación depende de infinidad de factores relacionados con el tipo de religión, origen y destino, el proceso migratorio mismo y las circunstancias que lo rodean. Algunos creyentes eligen permanecer en el centro de lo sagrado, otros circulan en la periferia, fuera de la institución religiosa, o bien son distantes y casi indiferentes a todo lo que les recuerde en forma vaga la fe en un dios. En ocasiones, la experiencia religiosa en el país receptor puede resultar incompleta, o hasta ingrata, de acuerdo con las subjetividades.

\section{Segunda parte}

\subsection{Cerca de - o en el centro- del círculo sagrado}

Inicio esta sección con los informantes que dejaron ver en sus discursos la centralidad de la creencia en sus vidas, cualesquiera que esta sea. No obstante, veremos que también están presentes ciertas constantes 
entre creyentes y el tipo de Iglesias a la que están afiliados. He observado una suerte de patrón, que consiste en un mayor entusiasmo e inclinación hacia la disciplina y perseverancia de los preceptos religiosos, si los inmigrantes pertenecen a una Iglesia protestante latina o bien a una católica, pero en la que pueden hablar en su lengua madre (español u otra lengua indígena), y en donde, además de contar con la promesa de la salvación del alma, reciben apoyo moral, la compañía de sus iguales, la oportunidad de revivir la memoria histórica de sus países o incluso de su pueblo natal y, desde luego, gozar de una atmósfera social amigable, afectiva y cálida, que funciona en forma muy parecida a las parroquias nacionales o National Parrish, que estudió el historiador Jay Dolan (1972), en la ciudad de Nueva York, entre católicos alemanes e irlandeses del siglo XIX.

Un caso revelador en donde la pastoral incide en forma directa en el fortalecimiento de la religiosidad en la vida diaria de los creyentes lo encontramos en el estudio realizado en Atlanta, Georgia, de 2006 a 2009. En 1999 la Parroquia de Santo Tomás el Apóstol, para mejorar el ministerio hispano (léase latino), acogió a un sacerdote mexicano llamado Jaime Molina y, poco tiempo después, llegó el padre Pancho, de nacionalidad argentina. La presencia de los sacerdotes latinos modificó la demografía de la feligresía. La membresía latina casi se triplicó: pasó de 15\% en 2000 a $43 \%$ en 2007, equivalente a 6000 familias registradas. Los euroamericanos ya no eran la mayoría: conformaban $39 \%$ del total. El padre Molina irradiaba un carisma formidable que captaba lo mismo a latinos que a euroamericanos; su exitoso ministerio no solo cautivó a los católicos, sino que fortaleció su fe. La pastoral que impulsaron los sacerdotes hispanohablantes era un ejercicio evangélico que rebasaba la ortodoxia institucional. Los latinos contaban con líderes espirituales que hablaban en su idioma materno y desde su tradición cultural, tal y como lo hicieran los alemanes e irlandeses en el siglo XIX en Nueva York, en las parroquias nacionales, de acuerdo con lo que asienta Dolan (1973) en su estudio. Frente a estos cambios inesperados e insólitos, los euroamericanos se sentían invadidos e incómodos en su propio espacio. Así lo expuso una voluntaria de la Iglesia en la entrevista: «Por alguna razón encontraron al padre Jaime y... entonces explotó el fenómeno. Fue el principio del fin».

Los latinos, que en su inmensa mayoría eran mexicanos, no solo eran más devotos, sino que llevaban su fe mucho más allá de las puertas del templo. Esto fue producto de la pastoral llamada Sistema Integral de Nueva Evangelización (SINE) ${ }^{7}$, que había sido implementada en la parroquia

7 El SINE inicia en México en 1974, cuando el padre Alfonso Navarro tiene una intensa experiencia espiritual que lo inspira a crear una forma de evangelizar capaz de integrar «todo 
desde 2000 por iniciativa del padre Javier Molina. Para dar una idea de los sentimientos de comunidad que se habían instalado en la congregación «hispana», daré algunos detalles. La misa dominical hispana se caracterizaba por una intensa y universal participación de los asistentes. Los niños del coro entonaban a ritmo ranchero, banda y baladas en español, bajo la batuta de un laico jalisciense. Numerosos recién nacidos eran presentados a la congregación y, si había algún cumpleañero entre los presentes, todos entonaban «Las mañanitas»; los fieles enlazaban sus manos al recitar el padrenuestro y, al finalizar el sacramento, todo mundo se dirigía al salón de la parroquia a tomar café y donas. Una actividad de esta pastoral consiste en promover interacciones frecuentes e intensas entre los seguidores y fomentar la creación de «comunidades de vida cristiana» formando grupos de 10 a 12 personas que se reúnen una noche a la semana para el estudio de la Biblia. Asimismo, impulsa a los integrantes a ser más activos y comprometidos en la evangelización y a llevar una vida cristiana en la cotidianidad que no se reduzca a los meros sacramentos. Cuando por las tardes las mujeres mexicanas llevaban a sus hijos al catecismo, se reunían a conversar entre ellas y en una de esas ocasiones relataron que en sus pueblos casi no asistían a la iglesia. Fue cuando conocieron la parroquia de Santo Tomás que comenzaron a tomar en serio su catolicismo. Estas mujeres provenían de pequeñas ciudades o localidades rurales en los estados de Guanajuato, Jalisco o Michoacán, en donde con frecuencia no había ni siquiera sacerdotes fijos, sino solo seminaristas o diáconos que visitaban las localidades en determinadas fechas. En este caso excepcional del siglo xxi, los inmigrantes mexicanos sí reivindicaron y reinventaron su fe católica en el país receptor, cosa que había sido casi olvidada en su lugar de origen.

Las ceremonias en español se multiplicaron a tales niveles que los euroamericanos sentían que los latinos habían tomado por asalto su territorio. Pero más importante todavía era que percibían con cierto grado de culpa e insatisfacción que los inmigrantes recientes eran más fervorosos que ellos y por ende mejores católicos. Así lo expresó otra voluntaria de la parroquia cuyos abuelos eran inmigrantes italianos:

cuando mis abuelos llegaron, era gente que no tenía instrucción. Escuchaban todo lo que el sacerdote les decía. Y cuanto más educados nos volvimos los católicos estadounidenses, esta iglesia se fue transformando. La concepción de espiritualidad cambió. Vamos a misa por razones casi diferentes que los [inmigrantes]. Lo interesante

para todos» en una parroquia. El padre Molina había practicado esta pastoral durante diez años en México. 
es que atiborran la iglesia para la misa y aquellos de nosotros más maduros y más educados en cierto modo, algo hemos perdido (el subrayado es mío).

Aunque he trabajado durante muchos años con una muestra «sesgada», en la que con frecuencia surge un porcentaje muy alto de «cristianos» o evangélicos, la cercanía o lejanía de los yucatecos migrantes de la vida religiosa también se explica a partir de las políticas eclesiales. Aquí me detengo a describir el tipo de liderazgo de un ministro presbiteriano, en la ciudad de San Francisco, California, destino de la mayoría de los mexicanos de Yucatán, que emigran a los Estados Unidos desde principios de la década de 1960.

Mauricio Chacón es originario de El Salvador. Desde muy joven emigró a Estados Unidos, donde fue formado como pastor en una institución presbiteriana en la ciudad de Chicago, el McCormick Theological Seminary. Con más de 30 años viviendo en el «país del norte» asimiló la cultura norteamericana sin renunciar a la propia. La capacidad intercultural adquirida le permite entender tanto a los latinos de su comunidad religiosa, como a la sociedad receptora en la que se insertan. Mauricio se hizo cargo de la Iglesia Presbiteriana de la Misión, en la ciudad de La Bahía de 1993, hasta principios de 2007, cuando fue asignado por la denominación a la ciudad de Houston, Texas. A pesar de que la congregación contaba solo con 60 miembros cuando la visité, su compromiso con diversos programas educativos, culturales y cívicos aparentaban la existencia de un mayor número de creyentes involucrados. Su trabajo como líder espiritual no se limitaba a atender a la congregación local, pues al mismo tiempo participaba del Seminario Pastoral de las iglesias de la Península de Yucatán y de México, realizaba múltiples visitas a su país de origen, formaba parte activa del Concilio Mundial de Iglesias, el Centro Ecuménico y de la Organización Internacional de Migrantes (OIM).

La enseñanza teológica del ministro salvadoreño fue emancipadora para las mujeres, pero demasiado liberal para algunos de los varones y para las autoridades de la Iglesia en México, también del sexo masculino. Según el propio ministro, el conservadurismo de la Asamblea de Iglesias Presbiterianas de Yucatán y de Chiapas no le permitió realizar cambios que eran necesarios. Por ejemplo, en San Francisco él mismo había ordenado a varias mujeres con el grado de ancianas, quienes desafortunadamente perdieron el rango al regresar a Yucatán. Considero que la personalidad, experiencia, disposición de servicio y calidad humana del pastor fueron atributos clave en el éxito de sus proyectos y en la promoción de una especial forma de religiosidad entre aquellos presbiterianos que se congregaban durante el periodo del reverendo Chacón. 
Asistir a una iglesia guarda una relación que supera el ámbito meramente espiritual y que está anclada en la vida aquí y ahora. Los casos presentados en las siguientes páginas pertenecen a migrantes originarios de Yucatán, México, que residieron o aún residen en San Francisco, California. Su discurso constata que los fieles se mantuvieron firmes en la fe, que fue parte de su equipaje al dejar el lugar de origen y, para cada uno de ellos, fue posible alcanzar los beneficios económicos y sociales, así como una relativa estabilidad familiar gracias a la Providencia. Los argumentos que expresaron los creyentes sirven también para mostrar que la fe y la devoción son independientes de la confesión de que se trate, puesto que tanto la práctica protestante como la católica tienen la capacidad de reactivar una intensa religiosidad en el migrante, como manifiesta María en su discurso ${ }^{8}$ :

Mi creencia nunca cambió. Hay mucha gente que cuando migra cambia de religión, yo llegando ahí empecé a averiguar dónde está la Iglesia presbiteriana. Fui anciana gobernante de la iglesia. Todo lo que yo tengo se lo debo a papá Dios.

Julio, de la misma región, también reconoció la importancia de las cosas sagradas en su vida: «Para mí, que me ayudó mucho Dios para poder trabajar. En lo que yo haga, yo lo pongo a él primero, por lo que he aprendido de él.

Y se puede decir lo mismo con respecto a Abraham cuando expresó su opinión:

Soy presbiteriano, cuando estaba en San Francisco busqué a los presbiterianos y me enrolé con ellos, estuve ascendiendo, trabajaba en el templo, los sábados nos juntábamos con los muchachos, tuve unos 30 donde exponía la palabra de Dios, compartíamos todos juntos. Me nombraron anciano de la Iglesia [...]. Continúo con la fe, continúo siendo presbiteriano, mi esposa igual, mis hijas igual.

Los católicos que están más cerca de las prácticas populares que de las oficiales u ortodoxas, aun cuando no cuenten con una pastoral tan eficiente como SINE, internalizan, a lo largo de incontables generaciones, una tradición ecléctica que incluye particularidades locales y/o prehispánicas, y entonces despliegan una religiosidad que se sostiene y persevera más allá de casi cualquier frontera. El lugar de origen, en este caso, de migrantes yucatecos, muestra esa persistencia de la devoción y su vinculación con la tradición migratoria del pueblo. Aquí son los mismos

8 Las respuestas de María, Julio y Abraham se derivan de entrevistas realizadas en Oxkutzcab y Dzan, Yucatán, en agosto, 2012, por I. Cornejo y P. Fortuny. 
emigrantes de generaciones más jóvenes quienes favorecen la continuidad de las fiestas patronales a través del envío de remesas «culturales», que se usan precisamente para hacer posible la realización de la novena ${ }^{9}$. De este modo, hallamos que los fieles que se inclinan hacia un catolicismo más tradicional (popular) que oficial e institucional, están enraizados a su creencia a tal grado, que han sabido transmitirla a lo largo de varias generaciones para que esta se fortalezca al contar con más capital para invertir en las múltiples celebraciones populares del terruño, como los gremios, novenas y rosarios. Así relata con gran orgullo don Ponciano: sus nietos, residentes en Estados Unidos desde hace muchos años, aún le tienen gran devoción a la Virgen de la Concepción y cada año «le mandan su ropa», además de recursos para que se lleve a cabo la novena en su honor, que empieza el 29 de noviembre y termina el 8 de diciembre. Don Ponciano y su esposa, desde una población sureña en el estado de Yucatán, pertenecen al gremio de la Virgen del Pilar; sin embargo, son los nietos los que han tomado la responsabilidad de cubrir los gastos que el festejo del gremio conlleva.

nosotros somos representantes [de] ellos, todos lo saben que aquí en la casa lo hacen, es de nosotros así, pero ellos mandan el dinero para que lo haga, todos colaboran. Pues está bien así, todavía no hay ninguna dificultad de nosotros con mis nietos.

A pesar de la separación de su familia, su casa y su cultura, la devoción por la Virgencita no ha disminuido en los nietos migrantes, más bien es la que permite en estos tiempos la reproducción de una vieja tradición de su pueblo, que de otra manera hubiera caído en desuso o al menos perdido el entusiasmo y la popularidad.

\subsection{En las márgenes de la creencia}

La mayoría de los inmigrantes trabajan de sol a sol. Un amplio sector de los entrevistados en varias ciudades de Estados Unidos tiene dos o más empleos. Esto significa trabajar sin descanso de ocho de la mañana a 11 o 12 la noche; seis de nuestros sujetos entrevistados en San Francisco, California, reconocieron haber consumido algún tipo de enervante para sobrellevar su dura jornada laboral. Las arduas y largas horas de trajines y

9 En la península de Yucatán se celebran novenas durante todo el año. Son dedicadas a santos o vírgenes de la región y consisten en nueve noches que se realizan cada semana en distintas viviendas de los devotos. Durante la velada se reza un rosario y algunas otras oraciones especiales. Al final el anfitrión invita a los asistentes a tomar alguna bebida y bocadillos. La novena o última noche es la más importante, ya que es auspiciada por la persona que organiza el evento. Al final de los rezos, en la fiesta se distribuye una cantidad considerable de diversos guisos y bebidas de la región. 
quehaceres en los empleos, la nostalgia por la familia y por el pueblo, los peligros que enfrentan, el cansancio y la rutina, hacen complicada y dolorosa la vida del migrante. En estas situaciones límite, como se ha visto en otros estudios (Fortuny Loret de Mola y Juárez Cerdi, 2007), la religión puede resultar un bálsamo en medio del caos, aunque no siempre es así. Estas son algunas razones que explicarían en parte por qué dejan de frecuentar la iglesia, o disminuyen su devoción y fervor, si bien casi nunca abandonan su religión vivida, entendida como aquella que «toma forma y se experimenta en el juego de los hechos y la existencia cotidiana» (Orsi, 1997, p. 9). Es, además, una relación dinámica que el creyente establece con la diaria existencia. O, como nos dice Simmel (1904), cuando señala la fluidez de la creencia que camina junto con las contradicciones de la vida práctica:

las personas verdaderamente religiosas no conciben la religión como la celebración de ciertos momentos específicos en sus vidas, como si fueran coronas de rosas que después de las festividades de un día se marchitan al anochecer.

Sin abandonar el paradigma del catolicismo popular y, a pesar de las distancias y diferencias que pueden existir entre los templos de su poblado y los que descubren en el destino, muchos creyentes permanecen fieles a sus devociones personales aprendidas desde la niñez. Tal es el caso de Mario, que tiene la costumbre de entrar a los templos católicos con un ramillete de flores y colocarlo a los pies de algún santo para que le devuelva la «salud espiritual». En Estados Unidos también hacía lo mismo. En la iglesia, exclama Mario: «solo voy a visitar los santitos, me persigno, hago una oración y le salgo». Su familia de origen es católica y con frecuencia organizan novenas y rezos colectivos, además de que por costumbre milenaria poseen uno o más altares en su vivienda. Mario, aún en la lejanía y soledad, continúa practicando el mismo estilo de piedad popular que le enseñaran sus padres y abuelos. No requiere del cura, de los sacramentos, la liturgia oficial o las enseñanzas ortodoxas para vivir su fe, ya que la lleva consigo como una extensión de su ser donde quiera que se encuentre.

En la sección anterior presenté varios testimonios de protestantes (presbiterianos) que conservan intacta su fe y le atribuyen los beneficios que han obtenido. Esto se explica en parte debido a que los líderes espirituales o pastores de las congregaciones protestantes locales han establecido importantes vínculos con sus contrapartes de San Francisco e incluso de Portland, Oregón, para fortalecer la fe, pero sobre todo para apoyar al creyente migrante y a sus familias en el pueblo ${ }^{10}$. En contraste, hasta 
donde se sabe, el clero católico yucateco ha hecho muy pocos esfuerzos para alentar, defender, proteger o asistir a sus ovejas que se encuentran en esa suerte de exilio. No es gratuito, por tanto, encontrar que los evangélicos que emigraron no solo no han perdido la fe, sino que la han fortalecido en tanto que muchos de los católicos entrevistados se han ido alejando cada vez más de su creencia y de la institución religiosa. Estas afirmaciones se evidencian en las palabras enunciadas por Manuel, de 30 años, que abandonó su terruño por primera vez en 1992 y que exclamó lo siguiente: «Yo soy católico, pero nunca iba a misa. Algunas veces entré a la iglesia, pero no a escuchar misa, nada más para hacer una oración».

Cuando el católico se ha alejado a tal grado de su creencia, puesto que ni siquiera participa de las fiestas patronales, su fe flaquea y resulta difícil que se sostenga, menos aún que se fortalezca en las condiciones de la migración. En este párrafo he concentrado testimonios de jóvenes migrantes originarios del estado de Yucatán, quienes emigraron a la ciudad de San Francisco, California ${ }^{11}$. Jorge sería este prototipo de católico frío o muy lejano de la fe. Era solo un muchacho en sus veintes cuando lo entrevistamos en 2003 en su lugar de origen. Manifestó que, mientras vivió en Estados Unidos, no frecuentaba la Iglesia (católica), porque tenía exceso de trabajo y le quedaba poco tiempo para todo lo demás. En su pueblo, en cambio, va casi cada domingo a la Iglesia (católica). Aún más lejos que Jorge, se encuentra David de la fe que le inculcaron sus padres, ya que él informó que durante los cinco años que duró su estancia en la ciudad de La Bahía, había ido a la Iglesia católica solo en dos ocasiones; finalmente, afirmó que a su regreso al pueblo dejó de asistir por completo. Un caso similar a los anteriores es el del joven Gilberto, quien admitió en San Francisco que visitaba la iglesia «en la Dolores ${ }^{12}$ cuando me siento un poco cansado mentalmente». En su relato Gilberto utilizó un tono exento de emoción o indiferente en lo que a su vida religiosa se refiere, aunque concedió que sus padres lo habían educado como católico. Fredman, ubicado también en las márgenes de lo sagrado, declaró en forma enfática que él no profesaba creencia alguna. Llegaba a la Iglesia (católica) muy de vez en cuando, y lo hacía por razones más sociales que espirituales en las fechas de Navidad y Año Nuevo, tanto en el pueblo como en San Francisco. José expresó sin dejar lugar a dudas que aunque era «católico [...] nunca fui a la iglesia [en mi pueblo]. Por último, Lenin de 25 años, durante los diez años que residió en San Francisco tampoco visitó nunca una iglesia.

11 Jorge, David, Gilberto, Fredman, José y Lenin fueron entrevistados en San Francisco, California, en mayo de 2005, por P. Fortuny y M. Solís y Oxkutzcab, Yucatán, por Pedro Chalé y M. Solís en 2004.

12 Esta iglesia es muy cercana al Distrito de la Misión. 
No obstante, al igual que José, se autoidentifica como católico y contó lo siguiente:

[Ahí en mi pueblo] no [asistía a ninguna iglesia]. Me acuerdo que pasaba e iba a correr alrededor de la iglesia, pero al frente hay un museo, parece una iglesia y veía que unos chavos pasaban y se persignaban. «¿Por qué se persignan?», les pregunté. «Somos católicos, es la iglesia». [La única vez que asistí a una iglesia en San Francisco] fue para una kermés para el viernes Santo, hacen convivio entre ellos y nos colamos, se llama Iglesia de los Dolores ${ }^{13}$.

Los siguientes entrevistados respondieron en forma muy similar a como lo hicieron los migrantes de Yucatán descritos en los párrafos anteriores. Aunque fueron consultados en otros espacios y tiempos ${ }^{14}$, estos ejemplos dan cuenta de la mayor o menor indiferencia que tienen hacia las cosas sagradas. Salvador, oriundo de Oaxaca, le preguntamos, cuando residía en Florida, qué era la religión para él. Respondió:

Más o menos es importante porque es digamos espiritual... El ser humano debe tener una religión espiritual, ya sea evangélica, cristiana o católica; como quiera, es espiritual, se concentra uno en Dios porque Él siempre existe. Existe el poder de Dios y todo se mueve por el poder de Dios».

Genaro es un inmigrante nacido en el estado de Hidalgo. Trabajaba en la pizca de tomate en los campos de cultivo en Immokalee, Florida. Resumió su creencia en pocas palabras: «No voy mucho a la iglesia, pero siempre es bueno andar viendo, pues, encomendarse a Dios, para que le ayude a uno». Jacinto era campesino en un pueblo de Michoacán y salió de México para emplearse en los campos de tomate en el suroeste de Florida, en donde la vida diaria es dura. Sin embargo, de acuerdo con sus palabras, este michoacano no requiere del consuelo divino como otros migrantes:

Cuando estaba en México iba a la iglesia y pues me sentía mal o me sentía triste y entraba a la iglesia, aunque estuviese sola, y salía muy calmado, con una paz y con otro estado emocional. Aquí he ido pocas veces a la iglesia, pero las veces que he ido es como si entrara a cualquier otro lugar, no siento esa misma vibración, no siento fe. Entonces casi ya no voy a la iglesia.

13 Lenin explicó que su familia extensa no participa en las fiestas católicas, aunque se identifican como mayas. Se trata de una familia secular que se reconoce en el folclore de su cultura maya, en buena parte una identidad adquirida durante su condición migratoria.

14 Las respuestas de Salvador, Genaro, Jacinto y Rigoberto se derivan de entrevistas realizadas en diversas temporadas de campo en Immokalee, Florida, de 2003 a 2006. 
Rigoberto es un joven amable y muy sociable de 19 años. Nació en una pequeña villa del estado de San Luís Potosí y, al igual que los informantes anteriores, también trabajaba como agricultor en Immokalee. Su idea de las cosas sagradas es un poco vaga, por decirlo de alguna manera. Estas fueron sus palabras textuales: «Mira, la religión viene siendo como una creencia de que uno cree en Dios, las imágenes, las fiestas patronales como se hace, se divierte la gente, comparte una alegría».

Estar en una iglesia es como tener un trabajo ${ }^{15}$

\subsection{Creer sin pertenecer (believing without belonging) ${ }^{16}$}

Tránsito es una inmigrante mexicana que «cree pero no pertenece». Cabe a la perfección en la categoría que define Davie (1994). Se siente incómoda en aquellas religiones estructuradas, tal y como asevera Hirschman (2004) en su artículo citado, aunque no muestra una actitud hostil hacia estas. Su falta de compromiso y participación en las instituciones se debe a una insatisfacción con la doctrina y la práctica. Este proceso de desinstitucionalización religiosa ha sido estudiado en México y en otros países latinoamericanos, pero sobre todo en Europa. Se manifiesta en un aumento de adhesión a formas de religiosidad sin mantener la pertenencia a una iglesia organizada. Al mismo tiempo, los creyentes adecúan las creencias y prácticas para recrear y reinventar su propio universo simbólico. Tránsito encarna la categoría de «religiosos sin religión» (Novaes, 2001), puesto que, sin estar afiliada a institución alguna, suele acudir a ellas. Nacida en Altamirano, Guerrero, es una mujer soltera de 46 años que llegó a Immokalee en 1972. Tenía tan solo 16 años cuando dejó la casa materna y se fue al «norte» para ayudar a sus 12 hermanos y a su madre. Durante más de 30 años trabajó en los campos agrícolas y remitía la mayoría de sus ganancias a su familia en México. Apoyó a varios de sus hermanos a emigrar y muchos de ellos viven hoy en ciudades del norte de Estados Unidos. En 2002, aún laboraba en las bodegas de tomate y naranja cuando había oferta de trabajo. A pesar de que consagró los mejores años de su vida a los campos de «la labor», no logró ahorrar, invertir en propiedades o bienes para vivir más cómodamente en su tercera edad. Aunque no asista a los servicios religiosos, esta inmigrante mexicana sí conoce las Iglesias del medio y los servicios asistenciales que prestan. Cuando la conocimos, se

\footnotetext{
15 Frase que expresó Tránsito durante la entrevista realizada en Immokalee, Florida, febrero, 2002, por E. Juárez y P. Fortuny.

16 Esta frase, acuñada por la socióloga inglesa Grace Davie en su libro Religion in Britain since 1945. Believing without Belonging, se derivó de su estudio realizado en Gran Bretaña sobre la etapa de la posguerra, en el que observa un creciente distanciamiento entre los creyentes y las instituciones religiosas, aunque ateos absolutos existen muy pocos y la gente no ha optado por abandonar la fe en forma definitiva.
} 
encontraba en el atrio de la Iglesia católica después de haber recibido una donación de ropa de Cáritas; mientras caminábamos con ella hacia la salida, unos bautistas conocidos la saludaron. Durante la conversación mencionó que también había asistido en varias ocasiones a la Iglesia pentecostal Bethel, ubicada en el mismo poblado. La razón fundamental que ofreció para explicar su no afiliación a una determinada comunidad religiosa es muy concreta y precisa. A ella le parece que «estar en una iglesia es como tener un trabajo». La religión institucional le parece impositiva, coercitiva e insatisfactoria en los niveles espiritual y personal. A pesar de su rechazo a la religión formal, su discurso contiene códigos pentecostales que quedaron como legado de su participación en una Iglesia cristiana de su pueblo natal cuando era solamente una niña. Suponemos que desde ahí aprendió a relacionarse con la divinidad sin intermediarios.

Con el objetivo de reforzar el argumento central del artículo, con respecto a las constantes transformaciones que experimentan los migrantes en el campo de las cosas sagradas, me resta mostrar algunas de las tendencias en el incremento del número de «no afiliados» que arrojan las encuestas aplicadas por el Pew Research Center en 2007 y 2014. En una publicación en línea de esta institución se define la situación de la noafiliación en esta forma:

at least by key measures of what it means to be a religious person. An extensive new survey of more than 35,000 U.S. adults finds that the percentages who say they believe in God, pray daily and regularly go to church or other religious services all have declined in recent years (Pew Research Center, 2015).

Según la encuesta, del total de la población estadounidense, los no afiliados aumentaron siete puntos porcentuales en siete años; es decir, pasaron de 16\% en 2007 a 23\% en 2014. En términos de millones en una escala de la totalidad de habitantes del país, el aumento fue de 19 millones (2007) a 56 millones de no afiliados en 2014. Entre los no afiliados, los ateos ascendieron a 3,1\%, los agnósticos llegaron a 4,1\% y los que se caracterizan por ser «nada en particular» o nones constituyen la mayoría de este grupo (16\%). En este estudio, nones no significa exactamente que ya no creen en Dios; sin embargo, como grupo, han disminuido sobremanera en el ejercicio de sus prácticas, como asistir a la iglesia o hacer oración; en otras palabras, la creencia y la práctica de acciones religiosas se ha debilitado en ellos.

Otros resultados de la encuesta revelan datos que refuerzan el enfoque sobre el movimiento de los inmigrantes (aunque aquí se incluyen, además de los mexicanos, los demás latinos y los de origen asiático). Seleccioné solo los cuatro estados de Norteamérica, de donde provienen algunos de 
los testimonios del trabajo. Para 2015, en California, los inmigrantes no afiliados se distribuían según la generación a la que corresponden en $22 \%$ de la primera, $20 \%$ de la segunda y $58 \%$ de la tercera. El estado de Texas tenía para el mismo año $17 \%$ de no afiliados pertenecientes a la primera generación de inmigrantes, $16 \%$ de la segunda y $67 \%$ de la tercera. Los inmigrantes no afiliados de Georgia se distribuían en $13 \%$ de la primera generación, $11 \%$ de la segunda y $77 \%$ de la tercera. Finalmente, el estado de Florida muestra resultados muy parecidos al estado tejano, con $19 \%$ en la primera generación, $15 \%$ en la segunda y $65 \%$ en la tercera. Los porcentajes que resultan de la correlación entre la categoría general de no afiliados, con generación de inmigrantes, en cuatro de los estados con mayor número de población mexicana o de origen mexicano, demuestran, en forma fehaciente, que son precisamente las nuevas generaciones o los jóvenes los que se están moviendo del centro a la periferia y de esta al abandono de la institución y posiblemente de la creencia. Considero que esta información cuantitativa aportada por la encuesta del Pew Research Center puede bien servir para comenzar a repensar el campo religioso como un territorio que atraviesa un proceso de transformación tal vez no del todo esperada.

\section{Conclusiones}

Los ejemplos presentados muestran la versatilidad y las múltiples posiciones que pueden ocupar los creyentes en el péndulo de lo sagrado. Posiblemente lo que proponía el modelo clásico de Handlin y Herberg y sus seguidores posteriores fue plausible hasta fines de los años 80 . En el presente, las circunstancias geopolíticas del mundo han cambiado. La frontera entre México y Estados Unidos inició una política de militarización desde los años 90 y ha ido incrementándose a partir de ese momento. Se invierten millones en la construcción de bardas, murallas, vallas cada vez más difíciles y riesgosas de atravesar. Aunado a las restricciones fronterizas y la multiplicidad de riesgos que corren los mexicanos y centroamericanos indocumentados que cruzan o intentar cruzar la frontera, están cada día más presentes las constantes deportaciones en casi toda la Unión Americana y en el mundo en general. Los migrantes son detenidos en Estados Unidos por haber cruzado como indocumentados o porque, según las leyes, cometieron algún delito leve, como carecer de licencia o seguro para conducir un vehículo. Este tipo de «violaciones» puede llevar a la deportación con la subsiguiente separación del padre o la madre de sus hijos. A pesar de los beneficios económicos que acarrean los inmigrantes en aquellos destinos en donde son empleados en los segmentos peor pagados del mercado laboral, sus condiciones y posibilidades de mejorar en general se han vuelto más complicadas, peligrosas $y$, en muchas 
ocasiones, imposibles. La supervivencia de los inmigrantes indocumentados, o en espera de su permiso de residencia u otra forma migratoria, en cualquier parte del mundo, se ha convertido en una tarea titánica con pocas esperanzas de alcanzar la meta.

Vivir en condiciones al límite, por tanto, podría constituir un caldo de cultivo para la reproducción religiosa en general y el acercamiento a la fe de los creyentes. Como muchos de los migrantes dicen, solo Dios puede ayudarnos. Es precisamente la religión, tanto la cristiana como el islamismo, la que exhorta a sus fieles a soportar el sufrimiento aquí en la tierra, para ganar el paraíso después de esta vida. Sin embargo, como hemos visto en los ejemplos del texto, esas promesas de salvación se van haciendo cada vez menos creíbles, sobre todo entre los jóvenes. En la sección que describe a aquellos que se encuentran en las márgenes de la religión se concentran varones menores de 30 años. Los mayores de 30 años y los adultos mayores aún conservan la esperanza de una vida eterna después de la muerte. La religión ha dejado de ser fundamental en la existencia de numerosos inmigrantes mexicanos y posiblemente en la de otros grupos nacionales en Estados Unidos, como la habían pensado los autores Herberg y Handlin del modelo clásico de mediados del siglo pasado. 


\section{REFERENCIAS BIBLIOGRÁFICAS}

Cadge, W., Levitt, P. y Smilde, D. (2011). De-Centering and Re-Centering: Rethinking Concepts and Methods in the Sociological Study of Religion. Journal for the Scientific Study of Religion, 50(3): pp. 437-449.

Davie, G. (1994). Religion in Britain since 1945: Believing without Belonging. Oxford: Blackwell.

Dolan, J. (1973). Immigrants in the City: New York's Irish and German Catholics. American Society of Church History, 41(3), pp. 354-368.

Fortuny Loret de Mola, P. (2002). The Santa Cena of the Luz del Mundo Church: A case of contemporary transnationalism. En H. R. Ebaugh y J. Chafetz (Eds.). Religion Across Borders: Transnational Religious Networks (pp.15-50). Walnut Creek: Altamira Press.

Fortuny Loret de Mola, P. y Juárez Cerdi, E. (2007). Espacios sagrados y seculares entre inmigrantes jornaleros en Immokalee, Florida. En A. Escobar Latapí (Coord.). Nación, Estado, comunidad: consolidación y emergencia en la emigración mexicana (pp. 227-250). Buenos Aires: Ciesas y Antropofagia.

Handlin, O. (1973). The Uprooted. The Epic Story of the Great Migrations that made the American People. Boston: Little, Brown and Company.

Herberg, W. (1960). Protestant, Catholic, Jew: An Essay in American Religious Sociology. Garden City, Nueva York: Anchor Books.

Hirschman, C. (2004). The Role of Religion in the Origins and Adaptation of Immigrant Groups in the United States. International Migration Review, 38, pp. 1206-1233.

Orsi, R. (1997). Everyday miracles: The study of lived religion. En D. Hall (Ed.). Lived Religion in America (pp. 3-21). Princeton: University Press.

(2002). The Madonna of 115 Street: Faith and Community in Italian Harlem, 1880-1950. New Haven: Yale University Press.

Pew Research Center (3 de noviembre de 2015). U.S. Public Becoming Less Religious. Recuperado de http://www.pewforum.org/2015/11/03/u-s-public-becoming-less-religious

Schwartz, J. (2004). Protestant, Catholic, Jew... Public Interest, 155, pp. 106-125.

Simmel, G. (2012). La religión. Barcelona: Gedisa.

Tweed, T. (1997). Our Lady of the Exile: Diasporic Religion at a Cuban Catholic Shrine in Miami. Nueva York: Oxford University Press. 
Warner, S. (1998). Immigration and Religious Communities in the United States. En W. Stephen y J. Wittner (Eds.). Gatherings in Diaspora: Religious Communities and the New Immigration. Filadelfia: Temple University Press.

Williams, R. B. (1988). Religions of Immigrants from India and Pakistan: New Threads in the American Tapestry. Cambridge: Cambridge University Press.

Recibido: junio de 2016 Aceptado: diciembre de $/ 2016$ 